Original Research Article

\title{
Analysis of prescription pattern of antihypertensive medication and adherence to Beers criteria in geriatric department of a tertiary care hospital in Mysuru
}

\author{
C. A. Priyanka ${ }^{1}$, Jayanthi M. K. ${ }^{1}$, Pratibha Periera ${ }^{2}$, Ranjith Raj ${ }^{1}$
}

\begin{abstract}
${ }^{1}$ Department of Pharmacology,
${ }^{2}$ Department of Geriatrics, JSS

Medical College, Mysuru,

Karnataka, India
\end{abstract}

Received: 24 September 2019

Revised: 14 November 2019

Accepted: 15 November 2019

\section{*Correspondence to: \\ Dr. C. A. Priyanka, \\ Email: priyankaambrish9@ \\ gmail.com}

Copyright: (C) the author(s), publisher and licensee Medip Academy. This is an openaccess article distributed under the terms of the Creative Commons Attribution NonCommercial License, which permits unrestricted noncommercial use, distribution, and reproduction in any medium, provided the original work is properly cited.

\begin{abstract}
Background: The objective of the present study was to evaluate the prescription pattern of anti-hypertensive drugs and adherence to Beers' criteria in geriatric department of JSS Hospital, Mysuru.

Methods: An observational, prospective, cross-sectional study was carried out in geriatric department. The basic demographic information and prescriptions of geriatric patients were studied. Descriptive analysis was used to present the results, prescriptions were analysed and checked for adherence to Beers' criteria.

Results: Out of 485 patients, $82.68 \%$ received monotherapy, $15.87 \%$ received 2 -drug combination therapy and $1.4 \%$ received 3 -drug combination therapy. Among patients receiving monotherapy, angiotensin receptor blockers (49.06\%) was the commonest antihypertensive class of drug prescribed. Telmisartan $(38.96 \%)$ was the commonest drug prescribed. Among 2-drug combination therapy angiotensin converting enzyme inhibitor and Calcium channel blockers were combined commonly. In 3-drug combination therapy angiotensin converting enzyme inhibitor, beta blockers and diuretics were combined commonly. $99.3 \%$ of prescriptions were adhered to 2015 American Geriatrics Society Beers criteria.

Conclusions: Almost $82 \%$ of the patients were treated with monotherapy. The trends in prescribing of anti-hypertensives were in favor of conventional ones such as Angiotensin receptor blockers, calcium channel blockers, angiotensin converting enzyme inhibitors, diuretics, beta blockers and centrally acting alpha agonists. $99.3 \%$ of prescriptions were in accordance with the American Geriatrics Society 2015 Updated Beers criteria.
\end{abstract}

Keywords: Hypertension, Anti-hypertensive treatment, Prescription pattern, Adherence, Geriatrics, Beers criteria

\section{INTRODUCTION}

Hypertension is an important contributor to the risk of cardiovascular disease and death, yet success in achieving blood pressure control has been limited. Many clinicians practice their own prescribing pattern in treating elderly patients with hypertension according to their clinical experience. Primary care physicians need to be empowered in appropriate and evidence-based management of hypertension in elders. Elderly patients appear to be particularly at risk of adverse drug reactions. More than $80 \%$ of adverse drug reaction causing admission in hospital is drug related hence in order to avoid potentially inappropriate drugs in elderly patients Dr. Mark Beers introduced Beers list. This study focuses on prescription pattern of anti-hypertensive medication in elderly patients and physicians' adherence to Beer's criteria for anti-hypertensives in prescribing medications.

Hypertension is more prevalent worldwide and is one of the most important risk factor for cardiovascular and cerebrovascular events. According to WHO health statistics 2012, the prevalence of hypertension in India 
was $23.1 \%$ in men and $22.6 \%$ in women in equal or more than 25 years age. ${ }^{1}$

Treating hypertension in elderly patients presents many theoretical and practical problems. The elderly are more sensitive than younger patients to the adverse effects of antihypertensive drugs, for various reasons, among which are age and disease related changes that can lead to altered pharmacodynamics and pharmacokinetics. Geriatrics go through multiple co-morbid conditions and hospitalized several times, this increases chances of polypharmacy and drug related issues which needs to be tackled. ${ }^{2}$ The goal of geriatric medicine is curing disease, eliminating or reducing symptoms, and improving quality of life and this is accomplished by optimal medication prescribing. Moreover, there is significant morbidity and mortality associated with suboptimal prescribing for geriatric age group. ${ }^{3}$

To elude such adverse effects in elderly inappropriate prescriptions should be avoided by identifying safer pharmacological alternatives which is often the best way to improve health outcomes. ${ }^{4}$

The primary approach to measure inappropriate prescribing is clinical reviews applying explicit criteria. Explicit criteria for defining and identifying drugs to avoid using for older people were recently developed by Dr. Mark Beer. The Beers criteria for potentially harmful inappropriate medication use in older adults, commonly called the Beers list, are guidelines for healthcare professionals to help improve the safety of prescribing medications in older adults. It highlights on describing medications that are unnecessary causing poly pharmacy, drug interactions, and adverse drug reactions. ${ }^{5}$

The criteria are used in geriatrics population to monitor and improve the quality of care. They are also used in training, research and healthcare policy to assist develop measures and document outcomes. These criteria include lists of medications in which the potential risks may be greater than the potential benefits for people 65 and older. By considering this information, practitioners may be able to reduce harmful side effects caused by such medications. The Beers criteria are intended to serve as a guide for clinicians and not as a substitute for professional judgment in prescribing decisions. ${ }^{6}$

This study focuses on prescription pattern of antihypertensive medication and parity of the same with Beers criteria in geriatric patients.

\section{METHODS}

This prospective, observational, cross-sectional, open, non-comparative study was conducted to describe the pattern of antihypertensive medications prescribed in elderly and to measure healthcare provider's adherence to treatment guidelines for geriatric age groups (2015 AGS
Beers' criteria) in the management of hypertension for patients. ${ }^{7}$ The data collected was obtained from convenience sampling of hypertensive patients' prescriptions utilizing a self-designed structured proforma. This cross-sectional study was undertaken from November 2016 to April 2018 in the outpatient department of geriatrics at JSS Hospital, Mysuru. This study was employed after obtaining ethical clearance from institutional ethical committee of JSS Medical College. The analysis was presented in terms of descriptive statistics.

\section{RESULTS}

The present study gathered 485 prescriptions of geriatric patients. It showed $258(53.1 \%)$ males with mean age of $73.2 \pm 4.9$ years and $227(46.8 \%)$ females with mean age of $75.3 \pm 4.7$ years (Figure 1).

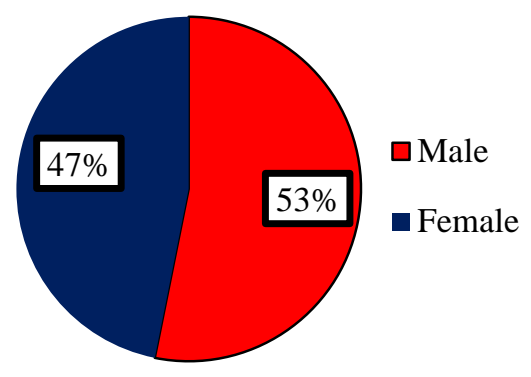

Figure 1: Distribution of patients according to age and gender.

In present study out of 485 patients, 401 patients (82\%) received monotherapy, 77 patients $(15.87 \%)$ received 2 drug combination therapy and 7 patients $(1.4 \%)$ received 3-drug combination therapy (Figure 2).

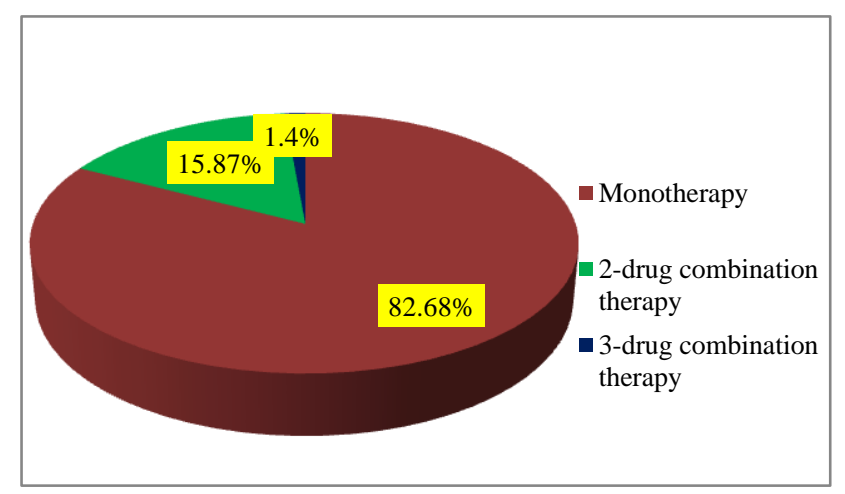

Figure 2: Drug utilization pattern.

Evaluating the use of monotherapy drugs, angiotensin II receptor blockers (ARB's) 78 (16.08\%) were commonly prescribed followed by calcium channel blockers (CCB's) 179 (36.9\%), angiotensin converting enzyme (ACE) inhibitors 78 (16.08\%), diuretics 49 (10.1\%), beta blockers $48(9.89 \%)$, and centrally acting alpha agonists $03(0.61 \%)$ (Figure 3). 
Table 1: Percentage distribution of patients receiving individual drugs.

\begin{tabular}{|lll|}
\hline Anti-hypertensive drug & $\mathbf{N}$ & $\%$ \\
\hline ACE inhibitors & & 13.4 \\
\hline Enalapril & 65 & 2.6 \\
\hline Ramipril & 13 & 38.96 \\
\hline Angiotensin receptor blockers & & 1.2 \\
\hline Telmisartan & 189 & 0.82 \\
\hline Losartan & 6 & \\
\hline Olmesartan & 4 & 25.77 \\
\hline CCB & & 10.72 \\
\hline Amlodipine & 125 & \\
\hline Cilindipine & 52 & 1.85 \\
\hline Beta blockers & & 5.7 \\
\hline Atenolol & 9 & 1.64 \\
\hline Metoprolol & 28 & 6.5 \\
\hline Diuretics & & 4.12 \\
\hline Hydrochlorothiazide & 8 & 1.64 \\
\hline Spironolactone & 32 & \\
\hline Furosemide & 20 & 0.61 \\
\hline Torasemide & 8 & \\
\hline Centrally acting alpha agonists & & (25) \\
\hline Clonidine & 3 & \\
\hline
\end{tabular}

Table 2: Evaluation of prescription using Beers criteria 2015.

\begin{tabular}{|lll|}
\hline Category of prescription screened & Number of prescriptions & $\%$ \\
\hline Prescription not adhered to Beers criteria & 3 & 0.61 \\
\hline Prescription adhered to Beers criteria & 482 & 99.3 \\
\hline
\end{tabular}

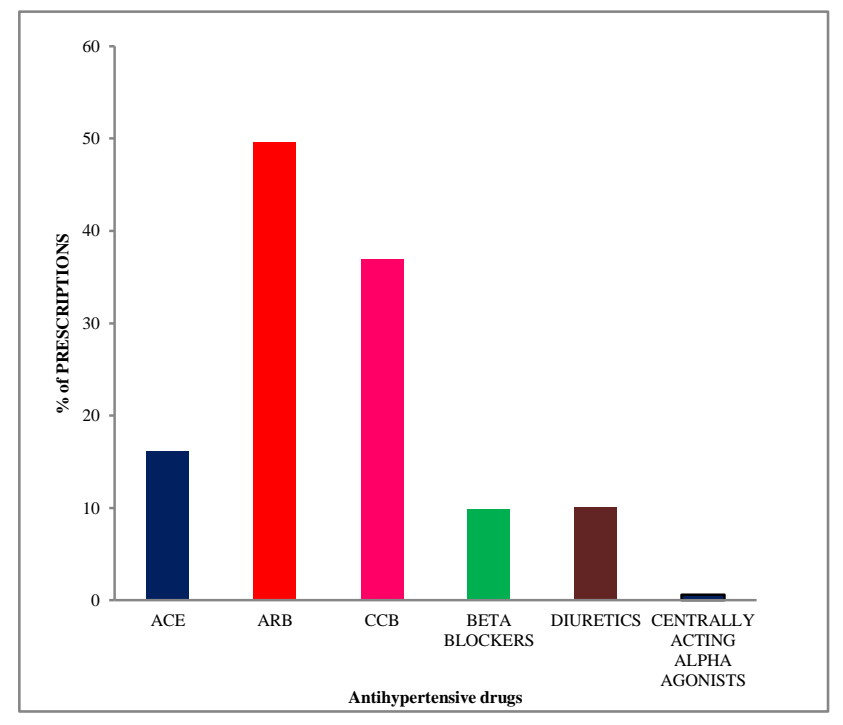

Figure 3: Monotherapy.

Out of 485 precriptions, 77 (15.87\%) preferred two drug combinations. ACE inhibitors and CCB's (16.6\%) were combined commonly followed by $\mathrm{CCB}+$ beta blockers $13.09 \%$, ACE+beta blockers $13.9 \%$, ARB+beta blockers $9.5 \%$, beta blockers+diuretics $9.5 \%, \mathrm{CCB}+$ diuretics $8.3 \%$, $\mathrm{ARB}+\mathrm{CCB} 7.14 \%, \mathrm{ACE}+\mathrm{ARB} 5.95 \%$, ACE+diuretics $5.95 \%$, ARB+diuretics $2.3 \%$. In three drug combination therapy ACE, beta blockers and diuretics $5.95 \%$ were commonly prescribed followed by $\mathrm{ARB}$, beta blockers and diuretics-2.3\% (Figure 4). 0.61\% prescriptions were not according to Beers criteria. $99.3 \%$ of prescriptions were in accordance with the American Geriatrics Society 2015 updated Beers criteria (Table 2).

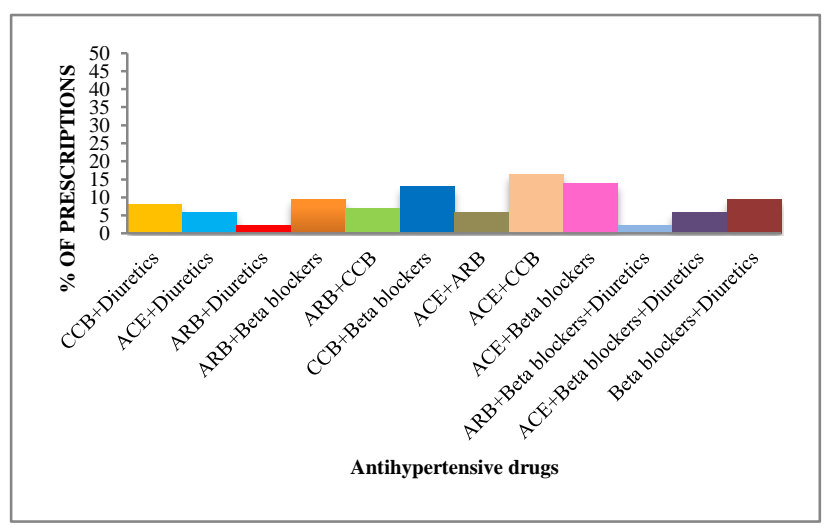

Figure 4: Combination therapy.

\section{DISCUSSION}

As per inclusion criteria we gathered 485 prescriptions during our study and found that prevalence of 
hypertension was $53.1 \%$ (258) among males and $46.8 \%$ (227) among females. Male preponderance was observed.

\section{Drug utilization pattern}

In present study out of 485 patients, 401 patients $(82 \%)$ received monotherapy, 77 patients $(15.87 \%)$ received 2drug combination therapy and 7 patients $(1.4 \%)$ received 3 -drug combination therapy. Monotherapy was preferred over combination therapy which was similar to study conducted by Konwar et al who reported in his study performed by analysing 270 prescriptions, 190 received monotherapy (70\%) and $80(30 \%)$ patients received combination therapy, in which $64(80 \%)$ received two drug and $16(20 \%)$ received three drug combination regime. ${ }^{8}$ Egan et al reports that hypertension is better controlled by combination therapy and it is a rational approach to decrease cardiovascular mortality but in present study monotherapy (82\%) was commonly used than combination therapy. The combination therapy was seen commonly in patients who came for follow up of uncontrolled blood pressure with monotherapy. ${ }^{9}$

\section{Monotherapy}

Evaluating the use of monotherapy drugs, ARB's 78 $(16.08 \%)$ were commonly prescribed followed by CCB's $179(36.9 \%)$, ACE inhibitors 78 (16.08\%), diuretics 49 $(10.1 \%)$, beta blockers $48(9.89 \%)$, and centrally acting alpha agonists $03(0.61 \%)$. On the contrary, study conducted by Sharma et al showed CCB's (31.03\%), were commonly prescribed followed by ACE inhibitors and ARB's. ${ }^{10}$

Preference for ACEIs, ARBs and CCB's by physicians' is possibly due to fact that ACEIs, ARBs and CCB's have better antihypertensive efficacy with minimal adverse effects and also provides cardiovascular and renal protection. Diuretics and beta blockers are used minimally because of adverse effects like hypokalemia, bradycardia and less well tolerated by geriatric patients.

Among individual drugs telmisartan 189 (38.96\%) was commonly prescribed followed by amlodipine 125 $(25.77 \%)$, enalapril $65(13.4 \%)$, cilindipine $52(10.72 \%)$, spironolactone $32(6.5 \%)$, metoprolol $28 \quad(5.7 \%)$, furosemide $20(4.12 \%)$, ramipril $13(2.6 \%)$, atenolol 9 $(1.85 \%)$, hydrochlorothiazide $8(1.64 \%)$, torasemide 8 $(1.64 \%)$, losartan $6(1.2 \%)$, olmesartan $4(0.82 \%)$, and clonidine $3(0.61 \%)$. Telmisartan is commonly prescribed because of its favourable tolerability and safety profile which is also supported by study conducted by Ruilope et al. ${ }^{11}$

\section{Two-drug combination therapy}

Out of 485 prescriptions, 77 (15.87\%) preferred two drug combinations. ACE inhibitors and CCB's (16.6\%) were combined commonly followed by $\mathrm{CCB}+$ beta blockers $13.09 \%$, ACE+beta blockers $13.9 \%$, ARB+beta blockers
9.5\%, beta blockers+diuretics 9.5\%, CCB+diuretics $8.3 \%, \quad \mathrm{ARB}+\mathrm{CCB} \quad 7.14 \%, \mathrm{ACE}+\mathrm{ARB} \quad 5.95 \%$, ACE+diuretics-5.95\%, ARB+diuretics 2.3\%. The study findings of Mika $M$ revealed that high-risk hypertensive patients who received ACE inhibitor combined with CCB experienced $20 \%$ less cardiovascular morbidity and mortality than patients on ACE inhibitor and thiazide type diuretic. $^{12}$

\section{Three- drug combination therapy}

Among 485 prescriptions, 7 (1.4\%) preferred three drug combinations. In 3-drug combination therapy ACE+beta blockers+diuretics $5.95 \%$ were commonly prescribed followed by ARB+beta blockers+diuretics-2.3\%. In study conducted by Sikidar et al, out of 300 prescriptions only $3 \%$ received three drug combinations which included ARB, CCB and diuretics. ${ }^{13}$ Three drug combination therapy was restricted to patients with uncontrolled hypertension when treated with monotherapy and two drug combination. Combination therapy acts through more than one mechanism which helps in more effective blood pressure control. In trials like Action in diabetes and vascular disease; Preterax and Diamicron-MR controlled evaluation (ADVANCE), the combination of an ACE inhibitor and a thiazide-like diuretic given to patients with type 2 diabetes reduced the incidence of diabetes-related complications and in trial Hypertension in the very elderly trial (HYVET), the administration of the same combination conferred lower rates of cardiovascular events. $^{14}$

\section{Evaluation of prescription using american geriatric society Beers criteria 2015}

Our study shows that most frequently prescribed classes of drugs are ARBs followed by CCB's, ACE inhibitors, diuretics and beta blockers alone or in combination. $0.61 \%$ prescriptions were not according to Beers criteria. $99.3 \%$ of prescriptions were in compliance with the American Geriatrics Society 2015 updated Beers criteria which recommend avoidance of potentially harmful inappropriate medications like peripheral alpha blockers, central alpha agonists and nifedipine in older adults. Many studies have been carried out on checking prescriptions for potentially harmful inappropriate medication in elderly but our study aims only at potentially harmful antihypertensive medication to be avoided in geriatrics. Aparasu et al reported 5\% inappropriate prescriptions in a retrospective, crosssectional study, Willcox et al conducted a retrospective cohort study in which he reported $23.5 \%$ inappropriate prescriptions, Stuck et al reported $14 \%$ inappropriate prescriptions in a study conducted on community dwelling elderly. ${ }^{15-17}$

\section{CONCLUSION}

Hypertension is a noteworthy and usually asymptomatic chronic disease, for which optimal control and adherence 
to prescribed medication is required in order to reduce the perils of cardiovascular, cerebrovascular and renal disease. Auditing antihypertensive prescriptions patterns and checking its adherence to standard and current recommendations and guidelines are important steps for blood pressure control and reducing hypertension-related morbidity and mortality. In conclusion, present prescription pattern analysis showed that monotherapy was preferred over combination therapy. Among monotherapy Angiotensin receptor blockers were the most commonly prescribed class of drugs. $99.3 \%$ prescriptions analysed were appropriate and was in adherence to Beers' criteria. Inspite of these data and published guidelines towards treatment approach inconsistencies exist, because of which treating physicians sometimes have to individualize the therapy based on specific patient clinical needs and response to the treatment.

\section{ACKNOWLEDGEMENTS}

Authors wish to thank patients, Head of Department of Pharmacology and Head of Department of Geriatrics of JSS Hospital for guidance and support.

Funding: No funding sources

Conflict of interest: None declared

Ethical approval: The study was approved by the Institutional Ethics Committee

\section{REFERENCES}

1. WHO health statistics, 2012. Available at: http://www.who.int/gho/publications/world_health_st atistics /2012/en/. Accessed on 17 September 2019.

2. Jain S, Upadhyaya P, Goyal J, Abhijit K, Jain P, Seth $\mathrm{V}$, et al. A systematic review of prescription pattern monitoring studies and their effectiveness in promoting rational use of medicines. Perspectives Clin Res. 2015;6(2):86-90.

3. Joseph TH, Kenneth ES, Christine MR, Morris W. Suboptimal prescribing in older inpatient and outpatient. JAGS. 2001;49(2):200-9.

4. Christine MC. American Geriatrics Society updated Beers criteria for potentially inappropriate medication use in older adults. J Am Geriatr Soc. 2012;60(4):616-31.

5. Routledge PA, O’Mahony MS, Woodhouse KW. Adverse drug reactions in elderly patients. Br J Clin Pharmacol. 2004;57(2):121-6.

6. Beers criteria. Available at: https://en.wikipedia.Org /wiki/Beers_Criteria. Accessed on 21 November 2019.
7. By the American Geriatrics Society 2015 Beers criteria update expert panel. American Geriatrics Society 2015 updated Beers criteria for potentially inappropriate medication use in older adults. JAGS. 2015.

8. Konwar M, Paul PK, Das S. Prescribing pattern of antihypertensive drugs in essential hypertension in medicine out patients department in a tertiary care hospital. Asian J Pharm Clin Res. 2014;7(2):142-4.

9. Egan BM, Bandyopadhyay D, Shaftman SR, Wagner CS, Zhao Y, Yu-Isenberg KS. Initial Monotherapy and Combination Therapy and Hypertension Control the First Year. Hypertension. 2012;59(6):1124-31.

10. Sharma AK, Dahiya N, Kairi JK, Bharati SM. Prescription patterns of antihypertensive drugs in a tertiary care hospital in India. Int $\mathbf{J}$ Basic Clin Pharmacol. 2015;4(1):55-9.

11. Ruilope LM. Telmisartan for the management of patients at high cardiovascular risk. Curr Med Res Opin. 2011;27(8):1673-82.

12. Mitka M. CCB/ACE Inhibitor Dual Therapy for Hypertension Lowers Cardiovascular Risk. JAMA. 2008;299(19):2263-4.

13. Sikidar P, Chakravarty P, Purkayastha A, Tigga R. A study on prescribing pattern of antihypertensives in adult patients attending in a tertiary care hospital of Assam, India. Int $\mathbf{J}$ Basic Clin Pharmacol. 2016;5(3):975-8.

14. Gorostidi M, de la Sierra A. Combination therapies for hypertension-why we need to look beyond RAS blockers. Expert Review Clin Pharmacol. 2018;11(9):841-53.

15. Aparasu RR, Fliginger SE. Inappropriate medication prescribing for the elderly by office-based physicians. Ann Pharmacother.1997;31:823-9.

16. Willcox SM, Himmelsten DU, Woolhandler S. Inappropriate drug prescribing for the communitydwelling elderly. JAMA. 1994;272:292-6.

17. Stuck AE, Beers MH, Steiner A, Aronow HU, Rubenstein LZ, Beck JC. Inappropriate medication use in community-residing older persons. Arch Intern Med. 1994;154:2195-200.

Cite this article as: Priyanka CA, Jayanthi MK, Periera P, Raj R. Analysis of prescription pattern of antihypertensive medication and adherence to Beers criteria in geriatric department of a tertiary care hospital in Mysuru. Int J Basic Clin Pharmacol 2019;8:2669-73. 